\title{
Vaccine acceptance: How to build and maintain trust in immunization
}

\author{
Chandni Sondagar ${ }^{1}$, Ruotian Xu*, Noni E MacDonald ${ }^{2}$, Eve Dubé ${ }^{3}$
}

\begin{abstract}
In Canada, over $80 \%$ of parents choose to vaccinate their children. Although this may appear positive, it is one of the lowest vaccination rates in the western world, and does not meet the $95 \%$ coverage rate needed to prevent outbreaks of vaccine-preventable diseases such as measles. A recent national immunization survey showed approximately $50 \%$ of parents are concerned about potential side-effects from vaccines, $25 \%$ believe that a vaccine can cause the disease it was meant to prevent, and $13 \%$ think alternative practices could eliminate the need for vaccines. In addition, vaccine hesitancy-defined by its determinants: confidence, complacency and convenience-is on rise. To address the complacency and trust (confidence) components of vaccine hesitancy, four best practices to optimize trust in vaccines and promote vaccine acceptance are presented. The first best practice is to understand the concerns; this is done at a population level via research and at individual level via motivational interviewing. The second best practice is to address these concerns by effectively presenting science-based information. This is done at a population level by communicating research and at an individual level by applying this research to the specific concerns, values and norms of the individual. Third, present immunization as a social norm, both in educational materials and in conversations. Finally, resilience is fostered by planning ahead (both at a population level and for individual practitioners) to manage events that can undermine trust and drive negative vaccine concerns, such as a new vaccine being added to the routine schedule or the emergence of an unexpected adverse event. Building and maintaining public trust in immunization takes time. Healthcare practitioners must keep in mind that while trust is a key element in vaccine acceptance, it is not the only element; convenience and access can also impact vaccine uptake. Nurturing trust is but one part of increasing vaccine acceptance and this brief will focus on strategies to build and nurture trust.
\end{abstract}

This work is licensed under a Creative Commons Attribution 4.0 International License.

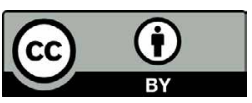

Affiliations

${ }^{1}$ Canadian Public Health Association, Ottawa, ON

${ }^{2}$ Department of Pediatrics, Dalhousie University, IWK Health Centre, Halifax, NS

${ }^{3}$ Quebec National Institute of Public Health, Québec, QC

*Correspondence: rxu@cpha.ca

Suggested citation: Sondagar C, Xu R, MacDonald NE, Dubé E. Vaccine acceptance: How to build and maintain trust in immunization. Can Commun Dis Rep 2020;46(5):155-9. https://doi.org/10.14745/ccdr.v46i05a09

Keywords: vaccination, vaccine acceptance, resiliency, confidence, evidence-based strategies

\section{Introduction}

Over $80 \%$ of parents in Canada accept immunization for their infants and children (1). Although this may appear positive, it is one of the lowest vaccination rates in the western world (2). As experience in the United States has recently shown, this rate is not high enough for community protection for vaccine-preventable diseases like measles, where $95 \%$ uptake is needed (3).

Studies have shown that many Canadian parents express concerns about vaccinations, and that not all parents are convinced of the accuracy or impartiality of the science $(4,5)$.

The results of a survey conducted by the Canadian Immunization Research Network in 2015 found that $70 \%$ of respondents believed that, as a parent, it is their role to question vaccines, and $19 \%$ considered themselves to be vaccine-hesitant (4). Surveys conducted in Canada show that a significant portion of Canadians has negative perceptions of vaccines, with approximately $20 \%$ still believing that vaccines are linked to autism (6-10).

Vaccine uptake is becoming a growing concern worldwide as we see vaccine-preventable disease outbreaks become more common. Measles, mumps and pertussis, once thought to be under control or near global eradication, are now all on the rise $(3,11-14)$. Despite the tremendous strides made in vaccine development, safety and access, vaccine hesitancy is not uncommon (1) and instead, is increasing. In 2019, it was declared as one of the top ten threats to global health by the 
World Health Organization (15). In Canada, vaccine hesitancy exists among those who are concerned about the safety of certain vaccines (especially towards new vaccines), who perceive that vaccines are for "mild" diseases, who question the utility of vaccination and lack trust in the information presented on vaccination $(4,6,16,17)$. While vaccine acceptance is the predominant behaviour (1), we need to aim for higher uptake rates to prevent vaccine-preventable diseases.

To improve vaccine uptake, we need to address the factors that drive negative vaccine concerns and to understand what fosters vaccine acceptance, or the intention to vaccinate (4). While it is equally important to understand and examine access or convenience barriers to accepting vaccines, this brief will mainly focus on trust and complacency (18). Both public health and healthcare providers are well positioned to build trust at both the population and individual levels.

The objective of this article is to identify four best practices to foster vaccine acceptance by building and maintaining trust in immunization. This is the fourth in a series of articles, produced by The Canadian Vaccination Evidence Resource and Exchange Centre (CANVax), an online database supporting immunization program planning and delivery through the identification of existing resources and creation of the new resources developed by a multidisciplinary group of professionals (19). This article builds on the previous three articles in the CANVax Briefs series (20-22), and will show how building resiliency, developing a communication strategy, and practicing motivational interviewing can foster vaccine acceptance.

\section{Understand the concerns}

For public health programs at a community level, the best way to understand the common concerns and vaccine hesitancy is through research. Research has shed light not only on the concerns of vaccines, but also on how social media can amplify these concerns, leading to vaccine hesitancy. A 2014 study, for example, demonstrated that $40 \%$ of mothers hesitated to have their child vaccinated, most frequently citing safety concerns such as 1) fear of adverse effects and 2) concerns that too many vaccines are being given at once, and that this may weaken a child's immune system (16). In the most recent 2017 Childhood National Immunization Coverage Survey (1), 52\% of parents and guardians indicated concerns about potential side effects from vaccines and $25 \%$ thought that a vaccine could cause the same disease that it is meant to prevent. In addition, a small number of parents and guardians (13\%) believed that complementary and alternative practices such as homeopathy or chiropractic treatments could eliminate the need for vaccines.

Research has also shed light on factors driving vaccine hesitancy. Advances in social media and internet-based communication technologies over the past decade have fostered the rapid and wide dissemination of information to large audiences, connecting individuals and communities well beyond their local geographies $(23,24)$. In addition, it has been found that negative concerns of vaccines tend to be remembered more easily (25) and to spread farther and faster than positive comments (26). These factors have amplified vaccine hesitancy (27).

While this research is helpful in anticipating a range of possible concerns, it is important to identify the specific concerns of each individual. Motivational interviewing is a helpful client-centred technique for exploring concerns that patients and parents may have towards vaccines $(22,28,29)$. This type of interviewing focuses on working with the patient and parent rather than talking to them. Techniques involved in this approach include the use of 1) open-ended questions (What are your concerns?), 2) affirmation (I understand your concerns), 3) reflective listening (Your concerns are...) and 4) summarizing (To summarize...) (18).

\section{Address the concerns effectively}

For public health programs at the community level, communication research has identified four best practices (21). First, messages advocating too strongly for vaccination can be counterproductive, and may have the paradoxical effect of reinforcing reluctance to accept immunization (30). Second, offering too much data should be avoided, as people stop paying attention. Remember that "facts tell but stories sell". Third, emphasizing scientific consensus on the benefit, safety and importance of vaccines can reduce concerns (31). For example, a healthcare provider can identify the side effects of the HPV vaccine, but then note that these are very rare and, in fact, the HPV vaccine is $99.9 \%$ safe. Framing this fact as a positive $(99.9 \%$ safe versus $<0.1 \%$ side effects) is also important, as the negatives are disproportionately heard and remembered (32). Fourth, the message should be tailored to key populations in a community in a way that aligns with their core values (18). For example, when discussing the benefits of HPV vaccines with those who belong to certain religious groups, it may be preferable to emphasize how HPV vaccine protects against certain cancers. These tailored narratives have been shown to change people's attitudes toward vaccines $(33,34)$. Finally, evaluation of any information material to identify areas for improvement is an essential component of any communication program (18). It is important to test messages with the target population to ensure they are working as intended.

At an individual level, front-line healthcare providers continue to be the most trusted source for vaccination information. As such, once trust is established, provider recommendations often lead to vaccine acceptance and uptake $(6,35)$. To establish trust, healthcare providers must elicit, acknowledge and then address people's concerns. They must provide information in a constructive and reassuring way that is simple, clear and easy to understand (36). Jargon should be avoided; for example, the term "herd immunity" can be off-putting for some peopleconsider using the term "community immunity" instead. Stories can be used to help clarify messages. Sometimes sharing an experience of treating a child ill with a vaccine-preventable disease can bring the facts to life. 
It is important to know that the majority of parents choose to accept routine vaccinations because they want to protect their children (1). Often, once the information is provided, just a gentle nudge to emphasize the protection that vaccines provide is enough to lead to vaccine acceptance.

\section{Present immunization as a social norm}

Social norms are powerful drivers of human behaviours (37) and research has shown that presenting vaccinations as a social norm can reinforce and build support for vaccination. Know, however, that abiding by social norms can work the other way too. One study showed that parents who refused vaccination for their child reported that a larger fraction of their social network was opposed to vaccination, and that this social network bias predicted the parents' decisions better than the characteristics of the parents themselves (38). Thus, healthcare workers must support and give value to the decisions of parents, patients and communities who accept vaccines; they must stress that choosing to vaccinate protects not only the individual but also the wider community. This knowledge can foster acceptance, nurture support for immunization and grow resiliency in the face of anti-vaccine rhetoric (33).

Expanding on the idea of vaccine as the norm, research has shown that, at an individual level, introducing immunization in a presumptive manner promotes vaccine acceptance better than in a participatory manner (39). A presumptive approach could be phrased as follows: "Sarah is due for her routine vaccinations today." This is in contrast to a participatory approach: "What would you like to do about Sarah's vaccinations today?"

\section{Foster resilience by planning ahead}

To build public support for vaccines, there is a need to foster trust not only in vaccines, but also in the health system in general and in immunization programs in particular (18). Events that can undermine trust and drive negative vaccine concerns (40-42) include the following:

- The addition of a new vaccine, resulting in an increase in the number of vaccines being recommended

- A new emerging side-effect for a particular vaccine

- A lack of consistency in vaccine recommendations (for example, from one province to the next)

Research has identified that it is useful for public health professionals to work through a specific communications approach for each of these situations ahead of time, so that there can be a quick and constructive response that dispels concerns early. For programs at the community level, there are three key areas to consider (33). First, communication strategies need to be tailored to the different communities and to leverage existing information channels. This includes public health communications to frontline healthcare professionals, so they are kept up-to-date on any changes. Second, trust in vaccines must be built through transparency. For example, if there is a vaccine scare, such as a new adverse event following immunization, vaccine recall, media reports, or rumours about a vaccine, it is essential to be transparent about this in order to maintain vaccine acceptance and uptake. Healthcare workers should present the facts, explain how vaccines are monitored for safety and effectiveness and how risk is being minimized. Third, at both community and individual levels, the people who accept vaccination and demand access to vaccines should be positively valued and acknowledged-by identifying this behaviour as the social norm.

\section{Conclusion}

These four best practices to promote vaccine acceptance are 1) to understand the concerns about immunization, 2) to effectively address those concerns, 3) to present immunization as a social norm that provides protection to both individuals and communities and 4) to foster resilience by planning ahead on how to deal with events that may undermine trust in vaccines. Building and maintaining public trust in immunization in the face of anti-vaccine rhetoric, both public and private, will take time. Beyond building trust, healthcare providers need to be aware that convenience and access are also a part of vaccine acceptance, and that those will need to be addressed to improve vaccine uptake. For healthcare providers working at the community level and the individual level, much can be done to foster trust in vaccines, in the health system and in immunization programs.

\section{Authors' statement}

$\mathrm{CS}$ - Writing original draft, review and editing

RX - Writing, review and editing

NEM - Writing, review and editing

ED - Writing, review \& editing

\section{Conflict of interest}

C Sondagar worked as a Senior Project Officer on the Canadian Vaccination Evidence Resource and Exchange Centre (CANVax) project at the Canadian Public Health Association at the time this paper was first written.

$\mathrm{R}$ Xu works as a Project Officer on the CANVax project at the Canadian Public Health Association.

NE MacDonald received grants from the Public Health Agency of Canada, the World Health Organization, the Nova Scotia Health Research Foundation, the Canadian Institutes of Health Research, the Canadian Immunization Research Network, and the Social Sciences and Humanities Research Council of Canada. She is a member of the CANVax Team.

E Dubé received grants from the Public Health Agency of Canada, the Quebec Ministry of Health and Social Services, les Fonds de recherche du Québec-Santé, the Canadian Institutes of Health Research, the Canadian Immunization Research Network and the Social Sciences and Humanities Research Council of Canada. She is a member of the CANVax Team. 


\section{Acknowledgements}

Production of the Canadian Vaccination Evidence Resource and Exchange Centre (CANVax) briefs has been made possible through funding from the Public Health Agency of Canada. Thank you to the many authors, immunization partners, and reviewers who contribute to CANVax.

\section{Funding}

The development of the Canadian Vaccination Evidence Resource and Exchange Centre Briefs is supported by the Immunization Partnership Funds of the Public Health Agency of Canada.

\section{References}

1. Public Health Agency of Canada. Highlights from the 2017 childhood National Immunization Coverage Survey (cNICS). Ottawa (ON): PHAC; 2020 (Accessed 201912-16). https://www.canada.ca/en/services/health/ publications/vaccines-immunization/vaccine-uptak e-canadian-children-preliminary-results-2017-childhood-nat ional-immunization-coverage-survey.html

2. UNICEF Office of Research. Child well-being in rich countries: a comparative overview. Innocenti Report Card 11. Florence (Italy): UNICEF; 2013. http://www.unicef-irc.org/ publications/pdf/rc11_eng.pdf

3. Feemster KA, Szipszky C. Resurgence of measles in the United States: how did we get here? Curr Opin Pediatr 2020 Feb;32(1):139-44. DOI PubMed

4. Dubé E, Gagnon D, Ouakki M, Bettinger JA, Witteman HO, MacDonald S, Fisher W, Saini V, Greyson D; Canadian Immunization Research Network. Measuring vaccine acceptance among Canadian parents: A survey of the Canadian Immunization Research Network. Vaccine 2018 Jan;36(4):545-52. DOI PubMed

5. Larson HJ, de Figueiredo A, Xiahong Z, Schulz WS, Verger P, Johnston IG, Cook AR, Jones NS. The State of Vaccine Confidence 2016: Global Insights Through a 67-Country Survey. EBioMedicine 2016 Oct;12:295-301. DOI PubMed

6. Dubé E, Bettinger JA, Fisher WA, Naus M, Mahmud SM, Hilderman T. Vaccine acceptance, hesitancy and refusal in Canada: challenges and potential approaches. Can Commun Dis Rep 2016 Dec;42(12):246-51. DOI PubMed

7. Mainstream Technologies. $67 \%$ say child care facilities should shun unvaccinated. Ontario: Scribd; 2015 (Accessed 201902-26). https://www.scribd.com/document/254901898/ Mainstreet-Technologies-Ontario-and-Vaccinatons-Poll
8. Mainstream Technologies. $66 \%$ say child care facilities should shun unvaccinated. Saskatchewan: Scribd; 2015 (Accessed 2019-02-26). https://www.scribd.com/doc/254907012/ Mainstreet-Technologies-Saskatchewan-and-Vaccinatons-Poll

9. Mainstream Technologies. $62 \%$ say child care facilities should shun unvaccinated. Manitoba: Scribd; 2015 (Accessed 2019-02-26). https://www.scribd.com/doc/255007188/ Mainstreet-Technologies-Manitoba-and-Vaccinatons-Poll

10. Mainstream Technologies. $65 \%$ say child care facilities should shun unvaccinated. Alberta: Scribd; 2015 (Accessed 201902-26). https://www.scribd.com/document/254904718/ Mainstreet-Technologies-Alberta-and-Vaccinatons-Poll

11. World Health Organization. Measles - Global situation. Geneva (CH): WHO; 2019 (Accessed 2019-12-17). https:// www.who.int/csr/don/26-november-2019-measles-global_ situation/en/

12. Dubey V, Ozaldin O, Shulman L, Stuart R, Maclachlan J, Bromley $L$, Summers A. Investigation and management of a large community mumps outbreak among young adults in Toronto, Canada, January 2017-February 2018. Can Commun Dis Rep 2018 Dec;44(12):309-16. DOI PubMed

13. Brown C. Measles resurgence comes to Canada. CMAJ News. 2019 Feb 26;191(11):E319. https://cmajnews. com/2019/02/26/measles-resurgence-comes-t o-canada-cmaj-109-5724/

14. Desjardins $M$, lachimov D, Mousseau S, Doyon-Plourde $P$, Brousseau N, Rallu F, Quach C. Clinical characteristics of pediatric pertussis cases, Quebec 2015-2017. Can Commun Dis Rep 2018 Sep;44(9):190-5. DOI PubMed

15. World Health Organization. Ten threats to global health in 2019. Geneva (CH): WHO; 2019 (Accessed 2020-01-17). https://www.who.int/news-room/feature-stories/ten-threat s-to-global-health-in-2019

16. Dubé E, Gagnon D, Zhou Z, Deceuninck G. Parental Vaccine Hesitancy in Quebec (Canada). PLoS Currents Outbreaks. 2016; Mar 7 (Edition 1). DOI

17. Berry NJ, Henry A, Danchin M, Trevena LJ, Willaby HW, Leask J. When parents won't vaccinate their children: a qualitative investigation of australian primary care providers' experiences. BMC Pediatr 2017 Jan;17(1):19. DOI PubMed

18. MacDonald N, Dubé È. Canadian Guidance on Addressing Vaccine Hesitancy to Help Foster Vaccine Demand and Acceptance. Ottawa (ON): CANVax; 2019. https://canvax. $\mathrm{ca} /$ canadian-guidance-addressing-vaccine-hesitancy-h elp-foster-vaccine-demand-and-acceptance-full

19. Canadian Public Health Association. The Canadian Vaccination Evidence Resource and Exchange Centre. Ottawa (ON): CANVax (Accessed 2019-12-15). https://www. canvax.ca 
20. MacDonald NE, Dubé E. Promoting immunization resiliency in the digital information age. Can Commun Dis Rep 2020 Jan;46(1):20-4. DOI PubMed

21. Dubé E, Gagnon D, Vivion M. Optimizing communication material to address vaccine hesitancy. Can Commun Dis Rep 2020;46(2/3):48-52. DOI

22. Gagneur A. Motivational Interviewing: A powerful tool to address vaccine hesitancy. Can Commun Dis Rep 2020;46(4):93-7. DOI

23. Larson HJ, Schulz WS, Tucker JD, Smith DM. Measuring vaccine confidence: introducing a global vaccine confidence index. PLoS Curr 2015 Feb;7. DOI PubMed

24. The Vaccine Confidence Project. The State of Vaccine Confidence 2015. 2015 (Accessed 2019-03-02). https://static1.squarespace.com/ static/5d4d746d648a4e0001186e38/t/5d75156b63cb4f2 65725de12/1567954291535/VCP_The-State-of-VaccineConfidence_2015.pdf

25. Baumeister RF, Bratslavsky E, Finkenauer C, Vohs KD. Bad is Stronger than Good. Rev Gen Psychol 2001 Dec;5(4):32370. DOI

26. Dunn AG, Leask J, Zhou X, Mandl KD, Coiera E. Associations Between Exposure to and Expression of Negative Opinions About Human Papillomavirus Vaccines on Social Media: An Observational Study. J Med Internet Res 2015 Jun;17(6):e144. DOI PubMed

27. Dunn AG, Surian D, Leask J, Dey A, Mandl KD, Coiera E. Mapping information exposure on social media to explain differences in HPV vaccine coverage in the United States. Vaccine 2017 May;35(23):3033-40. DOI PubMed

28. Reno JE, O'Leary S, Garrett K, Pyrzanowski J, Lockhart S, Campagna E, Barnard J, Dempsey AF. Improving Provider Communication about HPV Vaccines for Vaccine-Hesitant Parents Through the Use of Motivational Interviewing. J Health Commun 2018;23(4):313-20. DOI PubMed

29. Gagneur A, Battista MC, Boucher FD, Tapiero B, Quach C, De Wals $P$, Lemaitre T, Farrands A, Boulianne N, Sauvageau C, Ouakki M, Gosselin V, Petit G, Jacques $\mathrm{MC}$, Dubé Ė. Promoting vaccination in maternity wards motivational interview technique reduces hesitancy and enhances intention to vaccinate, results from a multicentre non-controlled pre- and post-intervention RCT-nested study, Quebec, March 2014 to February 2015. Euro Surveill 2019 Sep;24(36):1800641. DOI PubMed

30. Nyhan B, Reifler J, Richey S, Freed GL. Effective messages in vaccine promotion: a randomized trial. Pediatrics 2014 Apr;133(4):e835-42. DOI PubMed

31. van der Linden SL, Clarke CE, Maibach EW. Highlighting consensus among medical scientists increases public support for vaccines: evidence from a randomized experiment. BMC Public Health 2015 Dec;15:1207. DOI PubMed
32. Mostafapour M, Meyer SB, Scholer A. Exploring the effect of risk and benefit information provision on vaccination decision-making. Vaccine 2019 Oct;37(44):6750-9. DOI PubMed

33. Dubé $E$, MacDonald NE. Vaccination resilience: building and sustaining confidence in and demand for vaccination. Vaccine 2017 Jul;35(32):3907-9. DOI PubMed

34. Attwell K, Freeman M. I Immunise: an evaluation of a values-based campaign to change attitudes and beliefs. Vaccine 2015 Nov;33(46):6235-40. DOI PubMed

35. Dubé $E$, Laberge $C$, Guay M, Bramadat P, Roy R, Bettinger J. Vaccine hesitancy: an overview. Hum Vaccin Immunother 2013 Aug;9(8):1763-73. DOl PubMed

36. Alter AL, Oppenheimer DM. Uniting the tribes of fluency to form a metacognitive nation. Pers Soc Psychol Rev 2009 Aug;13(3):219-35. DOI PubMed

37. Brewer NT, Chapman GB, Rothman AJ, Leask J, Kempe A. Increasing Vaccination: Putting Psychological Science Into Action. Psychol Sci Public Interest 2017 Dec;18(3):149-207. DOI PubMed

38. Brunson EK. The impact of social networks on parents' vaccination decisions. Pediatrics 2013 May;131(5):e1397-404. DOI PubMed

39. Hofstetter AM, Robinson JD, Lepere K, Cunningham M, Etsekson N, Opel DJ. Clinician-parent discussions about influenza vaccination of children and their association with vaccine acceptance. Vaccine 2017 May;35(20):2709-15. DOl PubMed

40. Larson HJ, Cooper LZ, Eskola J, Katz SL, Ratzan S. Addressing the vaccine confidence gap. Lancet 2011 Aug;378(9790):526-35. DOI PubMed

41. MacDonald $N$, Picard $A$. A plea for clear language on vaccine safety. CMAJ. 2009 Mar 31;180(7):E2-3, 697-8. DOI

42. World Health Organization, Regional Office for Europe. Best practice guidance: How to respond to vocal vaccine deniers in public. Geneva (CH): WHO; 2017 (Accessed 2019-03-05). http://www.euro.who.int/en/health-topics/ disease-prevention/vaccines-and-immunization/ publications/2016/best-practice-guidance-how-to-respond -to-vocal-vaccine-deniers-in-public-2017 